\title{
$\alpha \mathrm{KAP}$ is an anchoring protein for a novel CaM kinase II isoform in skeletal muscle
}

\section{K.-Ulrich Bayer, Klaus Harbers ${ }^{1}$ and Howard Schulman²}

Department of Neurobiology, Stanford University School of Medicine, 299 Campus Drive, Stanford, CA 94305-5125, USA and

${ }^{1}$ Heinrich-Pette-Institut für Experimentelle Virologie und Immunologie an der Universität Hamburg, D-20251 Hamburg, Germany

${ }^{2}$ Corresponding author

e-mail: Schulman@cmgm.stanford.edu

$\mathrm{Ca}^{2+} /$ calmodulin-dependent protein kinase II (CaM kinase II) is present in a membrane-bound form that phosphorylates synapsin I on neuronal synaptic vesicles and the ryanodine receptor at skeletal muscle sarcoplasmic reticulum (SR), but it is unclear how this soluble enzyme is targeted to membranes. We demonstrate that $\alpha$ KAP, a non-kinase protein encoded by a gene within the gene of $\alpha$-CaM kinase II, can target the CaM kinase II holoenzyme to the SR membrane. Our results indicate that $\alpha \mathrm{KAP}$ (i) is anchored to the membrane via its $\mathrm{N}$-terminal hydrophobic domain, (ii) can co-assemble with catalytically competent CaM kinase II isoforms and target them to the membrane regardless of their state of activation, and (iii) is colocalized and associated with rat skeletal muscle CaM kinase II in vivo. $\alpha \mathrm{KAP}$ is therefore the first demonstrated anchoring protein for CaM kinase II. CaM kinase II assembled with $\alpha \mathrm{KAP}$ retains normal enzymatic activity and the ability to become $\mathrm{Ca}^{2+}$ independent following autophosphorylation. A new variant of $\beta$-CaM kinase II, termed $\beta_{M}-\mathrm{CaM}$ kinase II, is one of the predominant CaM kinase II isoforms associated with $\alpha$ KAP in skeletal muscle SR.

Keywords: anchoring/CaM kinase/sarcoplasmic reticulum/SH3 binding/targeting

\section{Introduction}

Protein kinases such as cAMP-dependent protein kinase (PKA), protein kinase $\mathrm{C}$ (PKC), and $\mathrm{Ca}^{2+} /$ calmodulindependent protein kinase II (CaM kinase II) phosphorylate many substrate proteins in order to coordinate diverse cellular responses to extracellular signals. But how is response specificity achieved with kinases designed to recognize many substrates? The targeting hypothesis and supporting data have provided a compelling mechanism for increasing the functional specificity of multifunctional kinases by appropriate intracellular targeting (Hubbard and Cohen, 1993; Mochly-Rosen, 1995; Pawson and Scott, 1997). Kinases can be spatially positioned near their substrates at all times, or translocate to their substrates subsequent to activation in order to improve speed and specificity in response to cell stimulation. Differential expression of anchoring proteins, some of which may directly modulate kinases, can generate distinct tissue-specific properties of a given kinase. Furthermore, compartmentalization of a kinase via an anchoring protein could affect accessibility of the kinase to its second messengers, thereby specifying a preferred receptor signaling route for its activation and/or modulating the amplitude of its basal and stimulated activities.

$\mathrm{CaM}$ kinase II orchestrates many cellular functions in response to $\mathrm{Ca}^{2+}$-based signals, including neurotransmitter synthesis and release, membrane excitability, synaptic plasticity, cell cycle and gene expression (reviewed in Braun and Schulman, 1995). Accordingly, the kinase has a wide tissue and subcellular distribution. There is compelling evidence for subcellular compartmentalization and targeting of the kinase. For example, although the kinase is largely soluble in transfected cells, it is also tightly bound to postsynaptic densities (PSDs) in neurons (Kelly et al., 1984), and interactions between CaM kinase II and unknown PSD proteins have been detected on SDS gels (McNeill and Colbran, 1995). A reversible translocation to this compartment was found to be regulated by activation and autophosphorylation of the kinase (Strack et al., 1997; Yoshimura and Yamauchi, 1997), and the high affinity of CaM kinase II for one of its substrates in the PSD, the NMDA receptor (Omkumar et al., 1996), could potenially play a role in this targeting. However, the only CaM kinase II targeting that is understood is that of isoforms that contain a demonstrated nuclear localization signal (NLS) (Srinivasan et al., 1994; Brocke et al., 1995). This involves a translocation into the nuclear compartment, rather than an anchoring protein, and is regulated by phosphorylation of the kinase near its NLS (Heist et al., 1998). CaM kinase II is also found in a membrane-bound form, e.g. on synaptic vesicles (Benfenati et al., 1992) and skeletal muscle sarcoplasmic reticulum (SR) (Campbell and MacLennan, 1982). We have chosen to ask how the kinase is targeted to the SR, where it modulates at least three intrinsic membrane proteins: the ryanodine receptor (the $\mathrm{Ca}^{2+}$ release channel) (Witcher et al., 1991; Wang and Best, 1992; Hain et al., 1995); phospholamban (a regulator of the $\mathrm{Ca}^{2+}$ pump protein) (Wegener et al., 1989); and the $\mathrm{Ca}^{2+}$ pump protein itself (Xu et al., 1993).

In mammals, numerous alternative spliced isoforms are generated from the four closely related $\alpha, \beta, \gamma$ and $\delta \mathrm{CaM}$ kinase II genes (Tobimatsu and Fujisawa, 1989; Karls et al., 1992; Mayer et al., 1993; Nghiem et al., 1993; Edman and Schulman, 1994; Brocke et al., 1995; Uriquidi and Ashcroft, 1995; Bayer et al., 1996). These isoforms have distinct but overlapping spatial and temporal expression patterns (Tobimatsu and Fujisawa, 1989; Burgin et al., 1990; Sakagami and Kondo, 1993), suggesting different specific functions. CaM kinase II isoforms contain a Cterminal domain that is responsible for the association of 


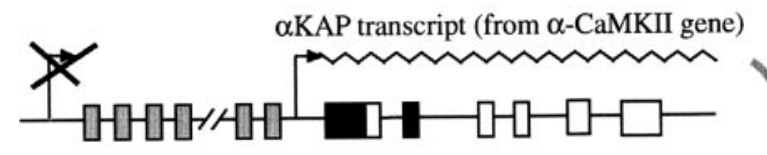

kinase transcripts (from $\beta$-, $\gamma$ - and $\delta$-CaMKII genes)

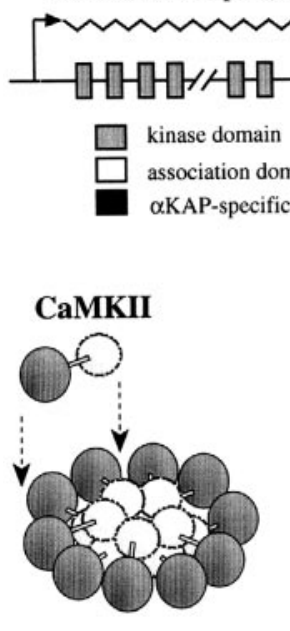

soluble

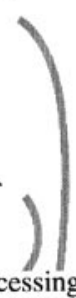

processing,
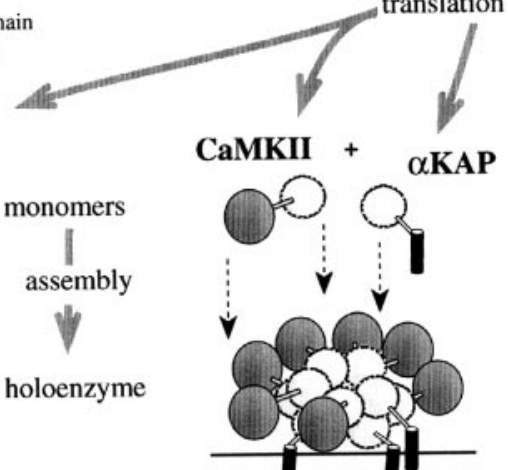

Fig. 1. A model for $\alpha \mathrm{KAP}$ as anchoring protein for CaM kinase II. The transcription of the CaM kinase II genes in skeletal muscle (top). Boxed areas indicate coding regions. $\alpha$-CaM kinase II is not expressed in skeletal muscle, however, usage of an intronal promoter and alternative splicing generates transcripts for $\alpha \mathrm{KAP}$, a non-kinase protein encoded by a gene within the gene of $\alpha$-CaM kinase II (Bayer et al., 1996). CaM kinase II monomers assemble via a C-terminal association domain to form soluble holoenzymes (left bottom panel). When $\alpha \mathrm{KAP}$ assembles with CaM kinase II, the resulting heteromeric holoenzymes contain its hydrophobic sequence and are targeted to cellular membranes (right bottom panel).

6-12 CaM kinase II molecules into a 'hub-and-spoke'like holoenzyme structure, with the association domains at the center and the catalytic and regulatory domains radiating outward (Figure 1, left bottom panel) (Kanaseki et al., 1991; Shen and Meyer, 1998). This unique arrangement constitutes the structural basis for the inter-subunit autophosphorylation of the regulatory domain that converts the enzyme into a $\mathrm{Ca}^{2+}$-independent or autonomous state (Hanson et al., 1994; Mukherji and Soderling, 1994). This autophosphorylation also leads to calmodulin trapping (Meyer et al., 1992) and is essential for the ability of $\mathrm{CaM}$ kinase II to act as a frequency decoder of $\mathrm{Ca}^{2+}$ oscillations (De Koninck and Schulman, 1998) and for long-term potentiation and hippocampal-based learning (Giese et al., 1998).

Intracellular targeting of signaling molecules such as PKA and PKC via anchoring proteins has been shown to be important for their proper function (Rosenmund et al., 1994; Johnson et al., 1996). Similarly, nuclear targeting of CaM kinase II was found to be essential for its action on gene expression in myocytes (Ramirez et al., 1997). Thus, insights into the cellular function and regulation of CaM kinase II await a molecular understanding of its targeting to the SR, PSD, cytoskeleton and other subcellular compartments. To date, however, no molecule serving as anchoring protein for CaM kinase II has been identified.

Here we identify the membrane-associated CaM kinase II isoforms in skeletal muscle, including a novel isoform

termed $\beta_{\mathrm{M}}$, and describe its co-localization with the CaM kinase II-related protein $\alpha$ KAP. $\alpha$ KAP is encoded by a gene within the gene of the brain-specific $\alpha$-CaM kinase II and consists of an $\mathrm{N}$-terminal hydrophobic domain followed by a C-terminus identical to the association domain of $\alpha_{\mathrm{B}}-\mathrm{CaM}$ kinase II, but lacking the catalytic domain (Figure 1, top) (Bayer et al., 1996). We identify $\alpha \mathrm{KAP}$ as a muscle-specific anchoring protein that can direct CaM kinase II to the SR membrane. The data presented support our proposed model shown schematically in Figure 1.

\section{Results}

\section{Identification of the microsomal CaM kinase II isoforms in muscle}

We examined the CaM kinase II isoform composition of rat skeletal muscle microsomes by immunoblot analysis to determine which isoform(s) might be responsible for the regulation of $\mathrm{SR}$ proteins such as the ryanodine receptor. The predominant immunoreactive protein in the microsomal fraction was a protein band detected with the $\beta$-specific antibody, although its molecular mass of $\sim 72 \mathrm{kDa}$ is larger than the previously identified $\beta$ isoforms. Based on their mobility in SDS-PAGE, the CaM kinase II isoforms detected in the microsomal pellet of skeletal muscle also include $\gamma_{\mathrm{B}}$ and $\delta_{\mathrm{D}}$ (Figure 2A). The $\beta$-immunoreactive band and $\gamma_{\mathrm{B}}-\mathrm{CaM}$ kinase II are highly enriched in the particulate fraction, whereas $\delta_{\mathrm{D}}$ was also present in the soluble fraction and an additional isoform, $\delta_{\mathrm{A}}$, was more abundant in the soluble fraction (Figure $2 \mathrm{~A}) . \alpha-\mathrm{CaM}$ kinase II is not expressed in muscle.

We used RT-PCR of skeletal muscle cDNA with $\beta$ $\mathrm{CaM}$ kinase-specific primers to determine whether the $\beta$-immunoreactive band is a $\beta$-isoform. Sequencing of the PCR products revealed a new $\beta$-isoform in skeletal muscle, termed $\beta_{M^{-}}$CaM kinase II, which differs from $\beta$-CaM kinase II by an insert in the variable region coding for an additional $12 \mathrm{kDa}$ peptide (Figure 2B; DDBJ/EMBL/ GenBank accession No. AF069731). The $\beta$-reactive band in the microsomal fraction is, in fact, the novel $\beta_{M}$ isoform, since expression of recombinant $\beta_{\mathrm{M}} \mathrm{CaM}$ kinase II in COS cells produces a $\beta$-immunoreactive protein with identical mobility in SDS-PAGE to the muscle protein (Figure 2A).

\section{$\alpha K A P$ is co-localized with CaM kinase II at membranes in skeletal muscle}

Since homomeric recombinant $\beta_{\mathrm{M}^{-}} \mathrm{CaM}$ kinase II, like other CaM kinase II isoforms, is not membrane bound (data not shown), we reasoned that the non-kinase protein $\alpha \mathrm{KAP}$, which contains a hydrophobic sequence (Bayer et al., 1996), may associate with and target soluble isoforms to the membrane. $\alpha$ KAP was localized exclusively in the particulate fraction (Figure 3A); the MGI serum used in a previous study (Bayer et al., 1996) crossreacted with an unrelated but similar-sized soluble protein, leading to its incorrect designation as a soluble protein (Bayer et al., 1996; Sugai et al., 1996). The membrane association of $\alpha$ KAP suggested by these experiments was further validated by a sucrose flotation assay: the vast majority of the particulate $\alpha$ KAP banded on top of the $45 \%$ sucrose cushion (Figure $3 \mathrm{~A}$ ). 
A

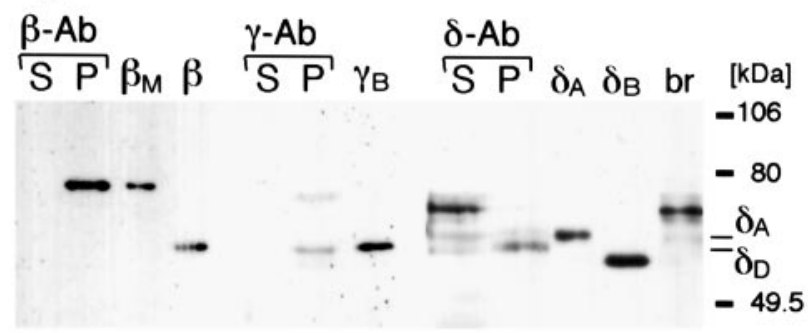

B

variable region of $\beta$-CaM kinase II

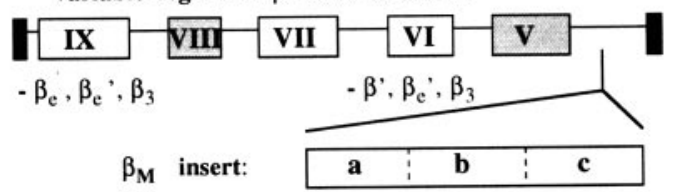

alignment of the Proline rich repeats of the $\beta_{M}$ insert:

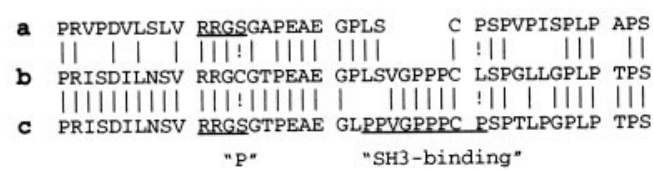

Fig. 2. The CaM kinase II isoforms in a microsomal fraction of skeletal muscle include the novel $\beta_{\mathrm{M}^{-}} \mathrm{CaM}$ kinase II. (A) A soluble cytosolic fraction $(\mathrm{S})$ and a particulate microsomal fraction $(\mathrm{P})$ of rat skeletal muscle were compared with recombinant $\mathrm{CaM}$ kinase II isoforms $\left(\beta, \beta_{\mathrm{M}}, \gamma_{\mathrm{B}}, \delta_{\mathrm{A}}\right.$ and $\left.\delta_{\mathrm{B}}\right)$ and a brain protein extract (br) by immunoblotting. Kinase was detected with an anti- $\beta-\mathrm{CaM}$ kinase II antibody (left panel), an anti- $\gamma$ antibody which crossreacts with $\beta$ isoforms (middle) and an anti- $\delta$ antibody (right). Note that $\delta_{\mathrm{D}}-\mathrm{CaM}$ kinase II (also termed $\delta_{4}$ ) is the only known $\delta$ isoform with a molecular mass significantly higher then $\delta_{\mathrm{B}}$ but lower than $\delta_{\mathrm{A}}$ thus facilitating its identification (Mayer et al., 1993; Edman and Schulman, 1994). (B) Structure and peptide sequence of the novel $\beta_{\mathrm{M}^{-}} \mathrm{CaM}$ kinase II. The variable region of the $\beta$-CaM kinase II gene (Karls et al., 1992) is schematically represented. The conserved exons are shaded, the $\beta_{\mathrm{M}}$ insert and regions lacked by individual isoforms are indicated. The $\beta_{M}$ insert consists of three proline rich repeats $(a, b$, c) which are homologous to each other and are aligned below. Two of those repeats are also present in $\beta_{3}$-CaM kinase II (Uriquidi and Ashcroft, 1995). Potential phosphorylation sites for CaM kinase II and PKA (P), and a putative SH3-domain binding region (SH3 binding) are marked.

Assessment of co-localization of $\alpha \mathrm{KAP}$ and CaM kinase II was refined by a sucrose step gradient of a microsomal preparation which suggested a similar fractionation pattern (Figure 3B). $\alpha \mathrm{KAP}$ and all kinase isoforms were present in fractions F2 to F5, with maximal levels in F4 [floating on $32 \%(\mathrm{~F} 2), 34 \%(\mathrm{~F} 3), 38 \%(\mathrm{~F} 4)$ or $45 \%$ (F5) sucrose]. There was some isoform-specific variation; the decrease from F4 to F5 was more significant for the $\beta$ - and $\gamma$-CaM kinase II, whereas the amount of the $\delta$ isoform was not different. The Ponceau S staining and the protein yields are consistent with the expected composition of the individual fractions (Figure 3C) (Saito et al., 1984; Leibovitch et al., 1993). Immunostaining with an antibody binding to all CaM kinase II isoforms and to $\alpha \mathrm{KAP}$ (antibody RU16; not shown; Benfenati et al., 1992) suggests that $\beta$ - and $\delta$-CaM kinase II are the predominant isoforms in microsomal preparations and are present in approximately equal amounts. The subunit ratio of total microsomal CaM kinase II to $\alpha \mathrm{KAP}$ is $\sim 1: 1$.
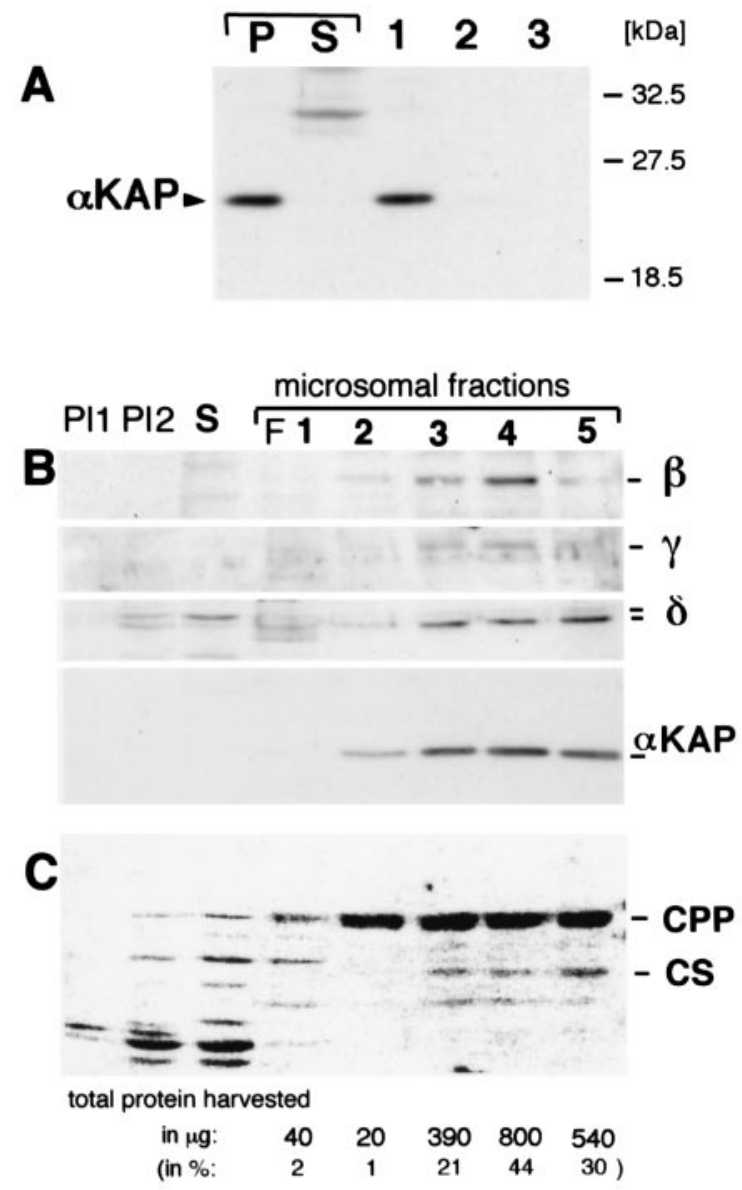

Fig. 3. $\alpha \mathrm{KAP}$ is particulate and co-localized with $\mathrm{CaM}$ kinase II in the SR. (A) A Western blot analysis of a particulate (P) and soluble (S) fraction of skeletal muscle using the NLS antibody is shown and the $\alpha \mathrm{KAP}$ band is indicated. $\alpha \mathrm{KAP}$ was also probed in fractions of a sucrose flotation assay (1, 15:45\% sucrose interphase; $2,45: 55 \%$ sucrose interphase; 3 , pellet). Similar results were found with two additional antibodies against other $\alpha \mathrm{KAP}$ epitopes (not shown).

(B) A microsomal preparation of rat skeletal muscle was fractionated on a sucrose density gradient and the fractions (F1-F5) were examined together with the cytosolic fraction (S) and the initial low speed pellets (P11 and P12) by immunoblot with antibodies to $\beta_{\mathrm{M}^{-}}, \gamma$-, and $\delta$-CaM kinase II and the NLS antibody to $\alpha$ KAP. F1-F5 are fractions collected from the interphases on top of the 26, 32, 34, 38 and $45 \%$ sucrose cushions, respectively. (C) Ponceau S staining of total protein. The $\mathrm{Ca}^{2+}$ pump protein (CPP) and the $\mathrm{Ca}^{2+}$ binding protein calsequestrin (CS) are indicated. Total protein content of fractions F1-F5 is indicated below. The composition of the fractions are: F1, mainly plasma membrane and T tubules, as indicated by the low concentration of CPP and high concentration of the $\mathrm{Na}^{+} / \mathrm{K}^{+}$ATPase (immunoblot not shown); F2, light SR and T tubules based on a high CPP concentration combined with the absence of CS; F3, F4, and F5, longitudinal and terminal cisternae of the SR based on the enrichment of both CPP and CS. The nuclear envelope is mainly present in F1 and in the low speed pellets P11 and P12, according to immunostaining with an antibody against nuclear pore complex proteins (data not shown).

These results indicate that $\alpha \mathrm{KAP}$ is localized primarily in the SR membrane. Little if any is present in the plasma membrane (F1), $\mathrm{T}$ tubules (F1) or the nuclear envelope (F1, Pl1 and Pl2). In fraction F5, where the terminal junctions of the SR are expected to be most enriched, the $\alpha \mathrm{KAP}$ concentration is slightly lower than in fraction F4 (longitudinal SR) (Figure 3B). This suggests that $\alpha \mathrm{KAP}$ is present in both terminal and longitudinal SR. Overall, the results clearly demonstrate an overlapping localization 


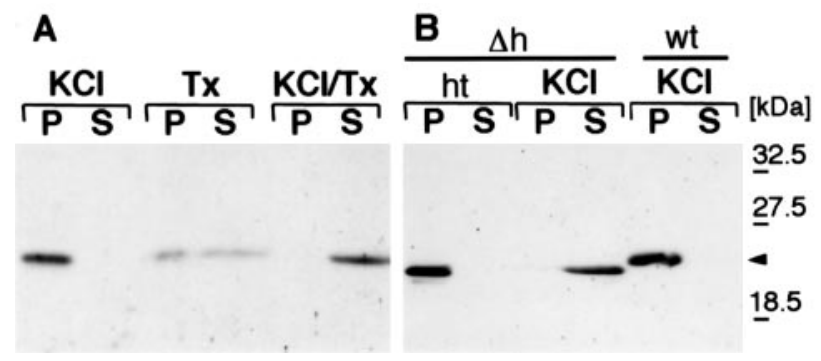

Fig. 4. $\alpha \mathrm{KAP}$ is membrane associated via its N-terminal domain. $\alpha \mathrm{KAP}$ was detected by immunoblotting using the NLS antibody. (A) Aliquots of the high speed pellets (P) and supernatants (S) of attempts to solubilize $\alpha \mathrm{KAP}$ from the particulate fraction of muscle using different treatments $(\mathrm{KCl}, 0.6 \mathrm{M} \mathrm{KCl}$; Tx, 2\% Triton $\mathrm{X}-100$; $\mathrm{KCl} / \mathrm{Tx}, 0.6 \mathrm{M} \mathrm{KCl}$ and $2 \%$ Triton $\mathrm{X}-100$ ) were analyzed. (B) COS cells overexpressing $\alpha \mathrm{KAP}$ lacking the N-terminal domain $(\alpha \mathrm{KAP} \Delta \mathrm{h})$ or wild-type $\alpha \mathrm{KAP}(\alpha \mathrm{KAP})$ were fractionated as indicated above, either under hypotonic conditions (ht) or in the presence of $1.1 \mathrm{M} \mathrm{KCl}$ $(\mathrm{KCl})$.

pattern of $\alpha \mathrm{KAP}$ and different $\mathrm{CaM}$ kinase II isoforms among the membranous fractions of skeletal muscle.

\section{$\alpha K A P$ is a CaM kinase II anchoring protein}

We hypothesized that $\alpha \mathrm{KAP}$ might serve as the anchor protein directing $\mathrm{CaM}$ kinase II to the SR membrane. Its C-terminal association domain might coassemble with the corresponding domain of CaM kinase II isoforms while its N-terminal hydrophobic domain would directly target the heteromer to membranes (Figure 1). We therefore tested the function of these two domains of $\alpha \mathrm{KAP}$.

$\alpha K A P$ is membrane-associated via its $N$-terminal domain. A sucrose flotation assay indicated that $\alpha \mathrm{KAP}$ is attached to membranes (Figure 3) and its solubilization properties are consistent with a direct membrane binding (Figure 4A). $\alpha$ KAP was not extracted from the particulate fraction by stepwise increases in the salt concentration up to $1.2 \mathrm{M} \mathrm{KCl}$ and remained insoluble even in $6 \mathrm{M}$ urea (not shown). A partial solubilization of $\alpha \mathrm{KAP}(\sim 50 \%)$ was obtained with detergent (2\% Triton X-100). However, complete solubilization was only achieved by a combination of detergent and salt (2\% Triton X-100/0.6 M KCl) (Figure 4A).

To test the hypothesis that $\alpha \mathrm{KAP}$ is membrane-anchored by its N-terminal hydrophobic domain, a recombinant $\alpha \mathrm{KAP}$ lacking this region $(\alpha \mathrm{KAP} \Delta \mathrm{h})$ was expressed in COS cells. In contrast to $\alpha \mathrm{KAP}$, no detergent was needed to solubilize $\alpha \mathrm{KAP} \Delta \mathrm{h}$ (Figure $4 \mathrm{~B}$ ), indicating that the $\mathrm{N}$ terminal domain is responsible for membrane association. However, under hypotonic conditions $\alpha \mathrm{KAP} \Delta \mathrm{h}$ was particulate, and the requirement of $\mathrm{KCl}$ for complete solubilization could indicate additional interactions with insoluble compounds.

$\alpha K A P$ can recruit CaM kinase II into the particulate fraction. The first evidence for an interaction of $\alpha \mathrm{KAP}$ and $\mathrm{CaM}$ kinase II was provided by the ability of $\alpha \mathrm{KAP}$ to recruit $\mathrm{CaM}$ kinase II into the particulate fraction (Figure 5). We expressed various isoforms of CaM kinase II $\left(\alpha, \beta, \gamma_{\mathrm{B}}\right.$ or $\left.\delta_{\mathrm{A}}\right)$ with either $\alpha \mathrm{KAP}$ or $\alpha \mathrm{KAP} \Delta \mathrm{h}$, and extracted the transfected COS cells in the presence of $\mathrm{KCl}$ to produce a soluble and particulate fraction. As when individually expressed, $\alpha \mathrm{KAP}$ was particulate and

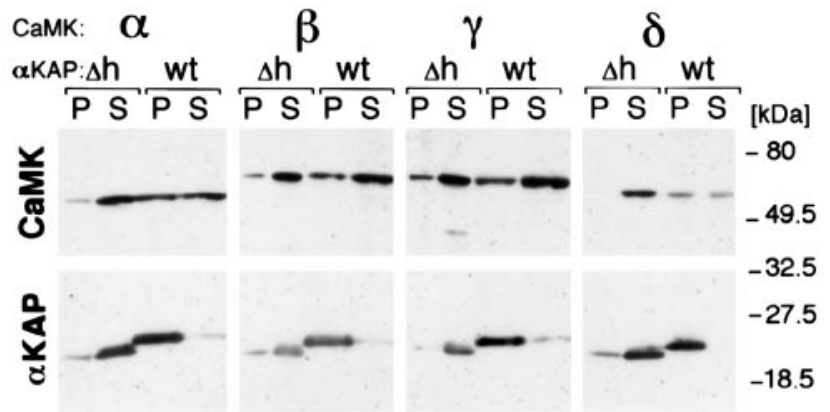

Fig. 5. $\alpha \mathrm{KAP}$ recruits different isoforms of CaM kinase II to the particulate fraction. COS cells were transfected with expression vectors for different CaM kinase II isoforms $\left(\alpha, \beta, \gamma_{B}\right.$ or $\left.\delta_{A}\right)$, either together with an $\alpha \mathrm{KAP} \Delta \mathrm{h}(\Delta \mathrm{h})$ or an $\alpha \mathrm{KAP}(\mathrm{wt})$ expression vector and fractionated into a particulate high speed pellet $(\mathrm{P})$ and a soluble supernatant $(\mathrm{S})$ in the presence of $1.1 \mathrm{M} \mathrm{KCl}$. Aliquots were subjected to Western blot analysis. $\alpha$ KAP was detected by the NLS antibody, the different $\mathrm{CaM}$ kinase II isoforms by calmodulin overlay.

$\alpha \mathrm{KAP} \Delta \mathrm{h}$ was soluble when coexpressed with the soluble kinase isoforms. However, the relative amount of $\mathrm{CaM}$ kinase II in the particulate fraction was significantly higher when coexpressed with wild-type $\alpha$ KAP than with $\alpha \mathrm{KAP} \Delta \mathrm{h}$.

\section{CaM kinase II binds to $\alpha K A P$ in an immobilized activity assay}

To investigate more directly whether $\alpha \mathrm{KAP}$ binds $\mathrm{CaM}$ kinase II, we used a modification of an immobilized kinase assay (De Koninck and Schulman, 1998). Recombinant $\alpha$ KAP containing a 12 amino acid hemagglutinin (HA) peptide tag at the C-terminus ( $\alpha$ KAPtag) was cotransfected with non-tagged $\alpha$-CaM kinase II, cells were extracted with $\mathrm{KCl} /$ Triton $\mathrm{X}-100$, adsorbed to PVC microtiter plates previously coated with anti-HAtag antibody, and kinase activity associated with the immobilized $\alpha$ KAPtag was measured. HA-tagged $\alpha$-CaM kinase II ( $\alpha$ CaMKtag) was similarly prepared and the immobilized enzyme, which retains normal kinase activity (De Koninck and Schulman, 1998), was used as positive control. A significant amount of kinase activity was immobilized only when $\alpha$-CaM kinase II was coexpressed with $\alpha$ KAPtag (Figure 6). If $\alpha-\mathrm{CaM}$ kinase II and $\alpha$ KAPtag were individually expressed and then mixed, no kinase binding was obtained (Figure 6). These results provide further evidence for the ability of $\alpha \mathrm{KAP}$ to bind CaM kinase II, and suggest that this interaction involves intracellular assembly as heteromultimers.

To immobilize the same CaM kinase II activity, an 4-fold higher CaM kinase II concentration was needed in an $\alpha \mathrm{CaMK}-\alpha \mathrm{KAPtag}$ binding reaction than in an $\alpha \mathrm{CaMKtag}$ binding reaction. All the experiments were carried out in high concentrations of salt and detergent, and this finding does not allow conclusions about the stoichiometry of the CaMK- $\alpha \mathrm{KAP}$ complexes. A high ratio of $\alpha \mathrm{KAP}$ to kinase subunits would interfere with inter-subunit autophosphorylation so we examined autophosphorylation in immobilized $\alpha \mathrm{CaMK}-\alpha \mathrm{KAPtag}$. Autophosphorylation was stimulated with $\mathrm{Ca}^{2+}$-calmodulin in the presence of $250 \mu \mathrm{M}$ ATP and the $\mathrm{Ca}^{2+}$-independent (autonomous) CaM kinase II activity generated by the autophosphorylation was assayed. Autophosphorylation 


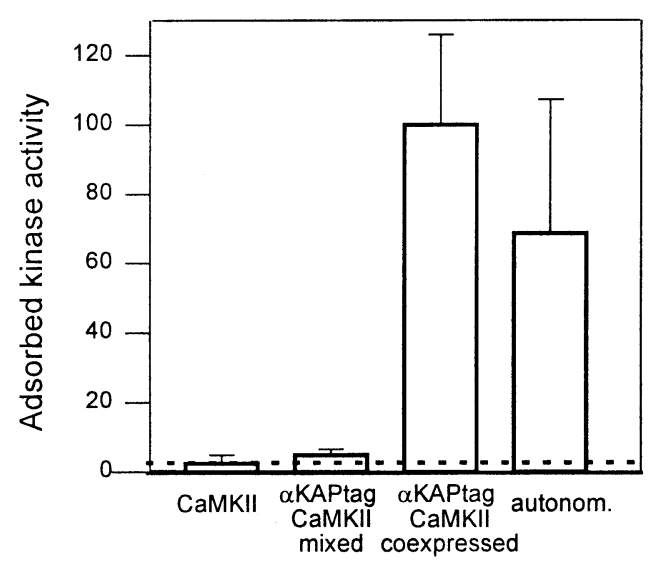

Fig. 6. $\alpha \mathrm{KAP}$ is associated with CaM kinase II as revealed by an immobilized kinase assay. Microtiter plates were coated with antiHAtag antibody and overlaid with overexpressed $\alpha$-CaM kinase II (CaMKII), a mixture of individually overexpressed HA-tagged $\alpha$ KAP $(\alpha$ KAPtag) and $\alpha-C a M$ kinase II, or coexpressed $\alpha$ KAPtag and $\alpha$-CaM kinase II. The overlaid solutions contained the same soluble kinase activities. The resulting $\mathrm{Ca}^{2+} /$ calmodulin-dependent kinase activity bound to the plates is presented relative to the observed activity with the $\alpha$ KAPtag and $\alpha$-CaM kinase II coexpressing extracts. Additionally, the autonomous activity after autophosphorylation of the bound kinase from this coexpressing extract was measured. The background of the assay is $12 \%$ and has been substracted. The error bars show the standard deviation, and the standard deviation of the baseline is given by a dotted line.

increased autonomous activity to $70 \%$ of the maximal $\mathrm{Ca}^{2+} /$ calmodulin-stimulated, indistinguishable from that seen with $\alpha$ CaMKtag alone, indicating that autonomous kinase activity can be generated when kinase subunits are in complex with $\alpha \mathrm{KAP}$ (Figure 6).

\section{CaM kinase II is associated with $\alpha K A P$ in skeletal muscle}

The association of $\alpha \mathrm{KAP}$ with CaM kinase II in rat skeletal muscle was tested by immunoprecipitation (Figure 7). Fraction F4 of a sucrose step gradient (Figure 3B) was extracted with salt and detergent, and a high speed supernatant was subjected to immunoprecipitation. Most of the tested antibodies against CaM kinase II or $\alpha \mathrm{KAP}$ failed to detect their antigen under conditions needed to solubilize $\alpha \mathrm{KAP}$. However, coprecipitation of $\alpha \mathrm{KAP}$ was obtained with the $\beta$-CaM kinase II-specific antibody CB $\beta 1$ (Figure 7). The data strongly suggest that $\alpha \mathrm{KAP}$ is colocalized and associated with $\beta_{\mathrm{M}^{-}} \mathrm{CaM}$ kinase II in vivo.

\section{Discussion}

The concept of subcellular targeting by anchoring proteins is of major importance for understanding the specificity of signal transduction. The work presented here constitutes the first description of an anchoring protein for multifunctional CaM kinase II. $\alpha \mathrm{KAP}$ exhibits three properties expected of anchoring proteins. (i) It is restricted to a specific cellular compartment, it is membrane bound and probably directly inserted into SR membranes by its $\mathrm{N}$-terminal hydrophobic domain (Figures 3 and 4). (ii) It binds CaM kinase II. This binding occurs within intact cells and not during extraction of transfected cells, since significant interaction was only detected after coexpression of $\alpha \mathrm{KAP}$ and CaM kinase II, but not when individually

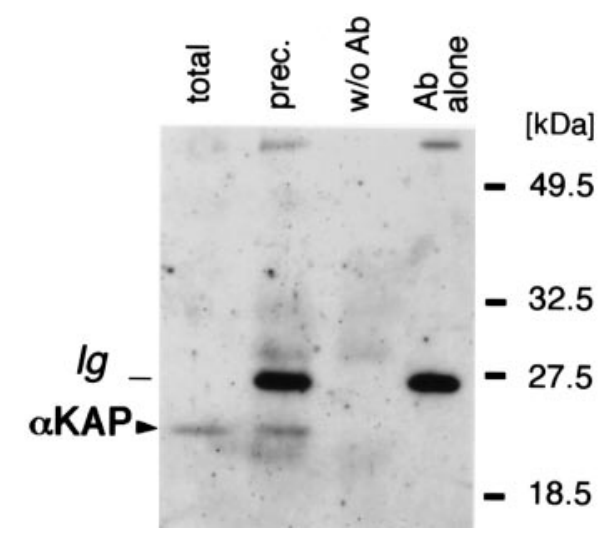

Fig. 7. $\alpha \mathrm{KAP}$ is binding CaM kinase II at membranes. An aliquot of the SR membrane-containing fraction F4 was extracted with salt and detergent, and a high speed supernatant (total) was subjected to immunoprecipitation with the $\beta$-CaMK-specific antibody $\mathrm{CB} \beta 1$ (prec.) or mock precipitation with PAS but without antibody (w/o Ab).

Aliquots of the high speed supernatant, the precipitates and an aliquot of the $\mathrm{CB} \beta 1$ antibody (Ab alone) were subjected to immunoblotting. Coprecipitation of $\alpha \mathrm{KAP}$ was detected using the NLS antibody. The amount of precipitates examined is equivalent to six times the amount of supernatant examined. The $\alpha \mathrm{KAP}$ band is indicated. The secondary antibody also detects an additional major band which corresponds to the $\mathrm{IgG}$ light chain of the precipitation antibody (Ig).

expressed proteins were mixed (Figure 6). (iii) It is responsible for the targeting of the novel $\beta_{\mathrm{M}^{-}} \mathrm{CaM}$ kinase II to the SR, since it co-immunoprecipitates with kinase extracted from SR membranes and the kinase does not have the physical properties of a membrane protein in the absence of $\alpha \mathrm{KAP}$. $\alpha \mathrm{KAP}$ is co-localized and associated with $\beta_{\mathrm{M}^{-}} \mathrm{CaM}$ kinase II, and probably with $\delta_{\mathrm{D}^{-}}, \delta_{\mathrm{A}^{-}}$and $\gamma_{\mathrm{B}}-\mathrm{CaM}$ kinase II, at the SR. Our proposed model is illustrated in Figure 1.

$\alpha \mathrm{KAP}$ and CaM kinase II associate with high affinity, maintaining their interaction at high salt and detergent concentrations used in the co-immunoprecipitation and in the immobilized kinase assay. Since $\alpha$ KAP contains the entire association domain of $\alpha_{\mathrm{B}}-\mathrm{CaM}$ kinase II (Lin et al., 1987; Brocke et al., 1995; Bayer et al., 1996), coassembly with kinase subunits is likely to utilize the same interactions that are involved in self-assembly of the kinase into homo- or heteromers (Shen and Meyer, 1998). This is consistent with the finding that $\alpha \mathrm{KAP}$ and $\mathrm{CaM}$ kinase II associate only if coexpressed and not when mixed after independent expression. There have been several reports of $\mathrm{CaM}$ kinase II interacting with proteins distinct from $\alpha$ KAP. The regulatory domain of $\alpha-\mathrm{CaM}$ kinase II interacts with synapsin I on synaptic vesicles, although in this case the kinase is membrane-associated by an unknown mechanism and may actually serve as an anchor for synapsin I (Benfenati et al., 1992). The physical properties of the CaM kinase II association with synaptic vesicles (Benfenati et al., 1996) make it attractive to propose that this targeting might also be achieved by an $\alpha \mathrm{KAP}$-like protein. A number of studies report interaction of the kinase with the cytoskeleton including PSDs, although no specific cytoskeletal protein has been implicated in these interactions (Sahyoun et al., 1985; Saitoh and Schwartz, 1985; McNeill and Colbran, 1995).

Families of specific anchoring proteins have been characterized for PKA and PKC, two other multifunctional 
protein kinases (reviewed in Hubbard and Cohen, 1993; Mochly-Rosen, 1995; Pawson and Scott, 1997). AKAPs bind the regulatory subunits of inactive PKA tetramers; after activation the catalytic subunits dissociate to the cytosol. By contrast, RACKs recruit PKC to particulate compartments only after the kinase has been activated in the cytosol. Thus, in both cases the locus of the activation and the action of the kinase is different, which may provide a biologically important delay. For CaM kinase II a reversible translocation to the PSD following activation and autophosphorylation has been described (Strack et al., 1997; Yoshimura and Yamauchi, 1997), although the molecular basis for such targeting is not known. Our data suggest that $\alpha$ KAP targets CaM kinase II to the SR and that both the association with the kinase and anchoring to SR occur independently of the activation state of the kinase. Anchoring to the SR membrane brings CaM kinase II near the entry site of $\mathrm{Ca}^{2+}$ and increases its concentration near physiological substrates, such as the ryanodine receptor and phospholamban. CaM kinase II has been shown to phosphorylate the ryanodine receptor, inactivating it and thereby modulating $\mathrm{Ca}^{2+}$ levels via a negative feedback mechanism (Wang and Best, 1992; Hain et al., 1995). A delay in this circuit would be introduced if the kinase were required to diffuse to the ryanodine receptor following activation; such a delay would be likely to alter the frequency at which $\mathrm{Ca}^{2+}$ waves could occur and might result in significant differences in the concentration of $\mathrm{Ca}^{2+}$ available for intracellular signaling. Anchoring of CaM kinase II by $\alpha$ KAP might serve not only to restrict substrate specificity in vivo but also play a role in determining the frequency at which $\mathrm{Ca}^{2+}$ waves could occur. The endogenous SR CaM kinase II has a different effect on the ryanodine receptor than exogenously added enzyme (Hain et al., 1995), suggesting that anchoring by $\alpha$ KAP might limit the access of the kinase to some of the possible phosphorylation sites on the substrate.

The hydrophobic N-terminus of $\alpha \mathrm{KAP}$ is responsible for its membrane association (Figure 4B). Rather than use an unrelated anchoring protein, CaM kinase II signaling has evolved to use a gene within the $\alpha$-CaM kinase II gene to introduce this hydrophobic domain into a protein that retains the association or self-assembly domain of the catalytically competent isoforms. Interestingly, the genes for two other $\mathrm{Ca}^{2+}$ /calmodulin-dependent protein kinases, CaM kinase IV and MLCK, also encode additional nonkinase products, calspermin and KRP, respectively (Means et al., 1991; Ohmstede et al., 1991; Collinge et al., 1992). However, these proteins probably do not function as anchoring proteins. In contrast, KRP may actually disrupt the localization of MLCK by competing for myosin binding (Shirinsky et al., 1993; Silver et al., 1997).

Database searches reveal homology of the hydrophobic domain of $\alpha$ KAP to signal peptides, which are responsible for import into the endoplasmic reticulum (reviewed in Schatz and Dobberstein, 1996). However, unlike classical signal peptides, $\alpha \mathrm{KAP}$ is not subject to posttranslational cleavage. Thus, the $\mathrm{N}$-terminal domain of $\alpha \mathrm{KAP}$ might represent a signal/anchor sequence combination, being responsible for both targeting to the SR and anchoring in its membrane, as described for cytochrome P-450 (Sakaguchi et al., 1987). Like $\alpha \mathrm{KAP}$, cytochrome P-450 lacks positive charges on the $\mathrm{N}$-terminal side of the hydrophobic signal sequence. In fact, introduction of basic amino acids at this position converts cytochrome P-450 into a secreted protein (Szczesna-Skorupa et al., 1988). Curiously, $\alpha$ KAP also contains a sequence identical to the nuclear localization signal that targets $\alpha_{\mathrm{B}}-\mathrm{CaM}$ kinase II to the nucleus (Brocke et al., 1995; Bayer et al., 1996). $\alpha \mathrm{KAP}$ is not targeted to the nucleus despite this sequence, perhaps because it is prevented by the dominant membrane anchoring function of the hydrophobic sequence. This distribution is more likely to occur if there is co-translational membrane insertion of $\alpha \mathrm{KAP}$ rather than an initial assembly of $\alpha \mathrm{KAP}$ with kinase into a holoenzyme, with a posttranslational membrane association.

An important role of anchoring proteins may be to bring different effector molecules together to form signaling complexes (reviewed in Pawson and Scott, 1997). $\alpha$ KAPCaM kinase II holoenzymes may bind NLS receptors. The binding of NLS receptor to $\alpha_{\mathrm{B}}$-CaM kinase II has recently been shown to be phosphorylation dependent (Heist et al., 1998). Since an identical NLS sequence with the critical phosphorylation site is also present in $\alpha \mathrm{KAP}, \alpha \mathrm{KAP}$ may function in a regulated sequestration of NLS receptors. Additionally, the insertion of $\beta_{\mathrm{M}}-\mathrm{CaM}$ kinase II contains a consensus sequence for SH3-domain binding, which was also found in the pancreatic $\beta_{3}$ isoform (Uriquidi and Ashcroft, 1995) and might represent a link to tyrosine kinase pathways, as described for a Ste20-related serine kinase (Anafi et al., 1997).

$\alpha$ KAP provides an example for a novel mechanism for achieving tissue-specific compartmentalization of effector molecules by differential use of the modular structure of proteins and genes. Examination of additional proteins interacting with $\alpha \mathrm{KAP}$ and CaM kinase II may promote further insight about control of intracellular signalling by protein networks.

\section{Materials and methods}

\section{Expression of $\alpha K A P$ and CaM kinase II in COS cells}

All expression constructs used are derivatives of $\mathrm{SR} \alpha$ and constructed as previously described (Nghiem et al., 1993; Edman and Schulman, 1994; Brocke et al., 1995; De Koninck and Schulman, 1998). For cloning of the $\alpha \mathrm{KAP}$ expression vector, a PCR product was generated using a murine skeletal muscle cDNA as template and the primer combination AK32-AK2, essentially as described (Bayer et al., 1996), and directly cloned in $\mathrm{PCR}^{\mathrm{TM}_{3}}$ (Invitrogen, Carlsbad, CA). The insert was then subcloned into the EcoRI site of $\mathrm{SR} \alpha$, and the DNA sequence was confirmed (Bayer et al., 1996). Note that the $\alpha \mathrm{KAP}$ homologue in rat (Sugai et al., 1996) is identical to the murine $\alpha \mathrm{KAP}$ (Bayer et al., 1996). The vector for expression of $\alpha \mathrm{KAPtag}$ was generated in a similar fashion, except that HA-tag was used as 3'-primer (5'-ACAGATCTGGGGCGCCCTCCGTCCTGCCGCATTATCCCTATGACGTGCCCGACTATGCCTGACCGCGGGGA-3') to insert an HA epitope tag at the C-terminus of $\alpha \mathrm{KAP}$. The $\alpha \mathrm{KAP} \Delta \mathrm{h}$ expression vector was constructed using a PstI-EcoRI fragment of the PCR product with the 5'-primer KP2 (5'-GTGCTGCAGACCGCCACCATGGCCTCCTCCACAGGAGGGAAGA-3') to delete the $21 \mathrm{~N}$-terminal hydrophobic amino acids. For generating a $\beta_{\mathrm{M}}-\mathrm{CaM}$ kinase II expression construct, a SacII-ApaI fragment of a RT-PCR product from skeletal muscle with the primer combination $35-2\left(5^{\prime}\right.$ ATCCTCACCACTATGCTGGCCACACG- $3^{\prime}$ ) and $\beta 3$ (Brocke et al., 1995) was inserted into the respective sites of the $\beta$-CaM kinase II expression vector.

COS-7 cells were transfected by the $\mathrm{CaPO}_{4}$ method as described (Srinivasan et al., 1994). In cotransfections, $10 \mu \mathrm{g}$ of $\alpha \mathrm{KAP}$ and $3 \mu \mathrm{g}$ of CaM kinase II expression vector were used for one $10 \mathrm{~cm}$ dish. The cells were harvested $68-76 \mathrm{~h}$ after transfection. 


\section{Microsomal preparations, sucrose step gradient and flotation assay}

The microsomal preparation and the sucrose step gradient followed a modification of previously described protocols (Saito et al., 1984; Leibovitch et al., 1993) carried out at $4^{\circ} \mathrm{C}$. Rat skeletal muscle (40 g) was homogenized in $160 \mathrm{ml}$ of $10 \mathrm{mM}$ HEPES $\mathrm{pH}$ 7.4, $5 \mathrm{mM}$ EDTA, $1.2 \mathrm{mM}$ EGTA, $10 \%$ sucrose, $1 \mathrm{mM}$ PMSF, $10 \mu \mathrm{g} / \mathrm{ml}$ leupeptin and $10 \mu \mathrm{g} / \mathrm{ml}$ pepstatin with $5 \times 20 \mathrm{~s}$ bursts in a Waring blender. The homogenate was then subjected to two low speed centrifugations (10 min at $4000 \mathrm{~g}$ and $20 \mathrm{~min}$ at $10500 \mathrm{~g}$ ) and the pellets were saved (P11 and P12). The supernatant was filtered through cheesecloth, supplemented with $\mathrm{KCl}$ to a final concentration of $0.5 \mathrm{M}$, stirred for $30 \mathrm{~min}$ and centrifuged for $45 \mathrm{~min}$ at $186000 \mathrm{~g}$ (40000 r.p.m. in a 45Ti rotor, Beckman). The cytosolic supernatant was saved and the microsomal pellet was resuspended in $4 \mathrm{mM}$ HEPES $\mathrm{pH} 7.4,0.4 \mathrm{M} \mathrm{KCl}, 26 \%$ sucrose, $1 \mathrm{mM}$ PMSF, $10 \mu \mathrm{g} / \mathrm{ml}$ leupeptin and $10 \mu \mathrm{g} / \mathrm{ml}$ pepstatin for further fractionation. The sucrose step gradient was composed of $4 \mathrm{ml}$ $45 \%$ sucrose as bottom layer followed by $7 \mathrm{ml}$ cushions of 38,34 and $32 \%$ sucrose. Ten milliliters of the microsomes resuspended in $26 \%$ sucrose were loaded on top and overlaid with $15 \%$ sucrose. The gradient was buffered with $4 \mathrm{mM}$ HEPES $\mathrm{pH} 7.4$ and contained $0.4 \mathrm{M} \mathrm{KCl}$. After $16 \mathrm{~h}$ centrifugation in a SW28 rotor (Beckman) at 22000 r.p.m., the interphases between the sucrose layers were harvested, and washed by dilution and recentrifugation. The protein concentrations of the rehomogenized pellets were determined by the method of Bradford (Bradford, 1976) using bovine serum albumin (BSA) as standard.

Microsomal pellets of murine skeletal muscle were prepared as described for rat, however in small scale using a VirTis ' 45' homogenizer. In the sucrose flotation assay, microsomes resuspended in 55\% sucrose were used as bottom layer of a gradient and overlaid with a $45 \%$ and a $15 \%$ sucrose cushion.

\section{Solubility tests}

COS cells were harvested in ice-cold phosphate-buffered saline and pelleted. Cells were disrupted by sonication in homogenization buffer (HB): 50 mM PIPES pH 7.0, 1 mM EGTA, 2 mM DTT, 10\% glycerol, $1 \mathrm{mM}$ PMSF, $10 \mu \mathrm{g} / \mathrm{ml}$ leupeptin and $10 \mu \mathrm{g} / \mathrm{ml}$ pepstatin. Skeletal muscle and brain were homogenized using a VirTis ' 45 '. The homogenates were then subjected to a $100000 \mathrm{~g}$ centrifugation (50 000 r.p.m. in a TLA100.2 rotor, Beckman) at $4^{\circ} \mathrm{C}$ for $1 \mathrm{~h}$, and the particulate high speed pellet was resuspended in $\mathrm{HB}$, restoring the original volume of the homogenate. For solubilization of $\alpha \mathrm{KAP}$ or $\alpha \mathrm{KAP} \Delta \mathrm{h}$, the HB was supplemented as indicated, and the homogenate was tumbled for $30-40 \mathrm{~min}$ at $4{ }^{\circ} \mathrm{C}$ prior to the second high speed centrifugation. When $\alpha \mathrm{KAP}$ was coexpressed with CaM kinase II, $1.1 \mathrm{M} \mathrm{KCl}$ was added before the fractionation.

\section{Immunodetection and calmodulin overlay}

Equal sample volumes or, in the case of the microsomal fractions, equal protein amounts were analyzed by Western blotting with immunodetection or calmodulin overlay using the ECL system (Amersham) as described (Srinivasan et al., 1994; Brocke et al., 1995). The protein transfer was routinely examined by Ponceau $\mathrm{S}$ staining of the blots. Antibody binding was carried out in the presence of $2 \%$ non-fat dry milk, calmodulin binding in presence of $1 \%$ BSA. All binding and washing solutions contained $0.1 \%$ Tween-20. The following antibodies were used: polyclonal antibodies with anti- $\alpha \mathrm{KAP}$ immunoreactivity NLS (gift of Dr M.Srinivasan, Department of Neurobiology, Stanford University School of Medicine, Stanford, CA), MGI (Bayer et al., 1996) and RU16 (gift from Dr A.Czernik, Laboratory of Molecular and Cellular Neuroscience, The Rockefeller University, NY) (Benfenati et al., 1992); the anti-CaM kinase II antibodies CB $\beta 1$ (anti- $\beta$; Gibco-BRL, Gaithersburg, MD), anti- $\gamma$ CaMKII (Santa Cruz Biotechnology Inc., Santa Cruz, $\mathrm{CA})$ and $\delta$ tail (anti- $\delta$; gift of Dr M.Srinivasan); an antibody against $\mathrm{Na}^{+} / \mathrm{K}^{+}$ATPase $(\alpha 3 \mathrm{NKA}$; gift from Dr W.J.Nelson, Department of Molecular and Cellular Physiology, Stanford University School of Medicine, Stanford, CA) (Mays et al., 1995) and an antibody against nuclear pore complex proteins (mAb 414; Babco, Richmond, CA).

\section{Immobilized kinase assay}

COS cells transfected with HA-tagged constructs were extracted with $\mathrm{HB}$ containing $0.6 \mathrm{M} \mathrm{KCl}$ and $2 \%$ Triton $\mathrm{X}-100$. The extracts were centrifuged and the $100000 \mathrm{~g}$ supernatants were used as the source of enzyme to be immobilized in microtiter plates and assayed as described (De Koninck and Schulman, 1998), with the exception that the binding reaction was carried out in the presence of $0.6 \mathrm{M} \mathrm{KCl}$ and $2 \%$ Triton $\mathrm{X}-100$. Non-specific activity was determined using extracts of nontransfected COS cells.

\section{Immunoprecipitation}

Fraction F4 of the sucrose step gradient was solubilized with Triton X$100-\mathrm{KCl}$ as described above. One hundred microliters $(40 \mu \mathrm{g}$ of total protein) were incubated with the $\beta$-CaM kinase II specific antibody $\mathrm{CB} \beta 1$ (1:330) for $1 \mathrm{~h}$ at $4^{\circ} \mathrm{C}$ on a roller, then $100 \mu \mathrm{l}$ of $50 \%$ protein A-Sepharose (PAS) containing 2.5\% BSA were added and the mixture incubated for an additional $1 \mathrm{~h}$. The PAS was harvested by centrifugation at $2000 \mathrm{~g}$ for $1 \mathrm{~min}$. The pellet was washed once in incubation buffer (HB supplemented with 2\% Triton X-100, $0.6 \mathrm{M} \mathrm{KCl}$ and 2.5\% BSA) and three times with $50 \mathrm{mM}$ PIPES pH $7.0,150 \mathrm{mM} \mathrm{NaCl}, 1 \mathrm{mM}$ EDTA and $1 \%$ Triton X-100. The pellet was boiled for $10 \mathrm{~min}$ in $100 \mu \mathrm{l}$ SDS-loading buffer, and a $15 \mu \mathrm{l}$ aliquot was analyzed by immunoblotting.

\section{Acknowledgements}

The antibodies RU16, $\alpha 3$ NKA and NLS were generous gifts from Dr A.Czernik, Dr W.J.Nelson and Dr M.Srinivasan, respectively. We are thankful to Dr L.Stryer for his helpful comments on the manuscript. The research was supported by NIH grant GM40600 and by Deutsche Forschungsgemeinschaft; K.-U.B. was supported by DFG research fellowship BA1647/1-1.

\section{References}

Anafi,M., Kiefer,F., Gish,G.D., Mbamalu,G., Iscove,N.N. and Pawson,T. (1997) SH2/SH3 adaptor proteins can link tyrosine kinases to a Ste20related protein kinase, HPK1. J. Biol. Chem., 272, 27804-27811.

Bayer,K.-U., Löhler,J. and Harbers,K. (1996) An alternative, nonkinase product of the brain-specifically expressed $\mathrm{Ca}^{2+} /$ calmodulin-dependent kinase II $\alpha$ isoform gene in skeletal muscle. Mol. Cell. Biol., 16, 29-36.

Benfenati,F., Valtorta,F., Rubenstein,J.L., Gorelick,F.S. and Greengard,P. (1992) Synaptic vesicle-associated $\mathrm{Ca}^{2+} /$ calmodulin-dependent protein kinase II is a binding protein for synapsin I. Nature, 359, 417-420.

Benfenati,F., Onofri,F., Czernik,A.J. and Valtorta,F. (1996) Biochemical and functional characterization of the synaptic vesicle-associated form of $\mathrm{Ca}^{2+} /$ calmodulin-dependent protein kinase II. Mol. Brain Res., 40, 297-309.

Bradford,M.M. (1976) A rapid and sensitive method for the quantitation of microgram quantities of protein utilizing the principle of proteindye binding. Anal. Biochem., 72, 248-254.

Braun,A.P. and Schulman,H. (1995) The multifunctional calcium/ calmodulin-dependent protein kinase II: from form to function. Аnnu. Rev. Physiol., 57, 417-445.

Brocke,L., Srinivasan,M. and Schulman,H. (1995) Developmental and regional expression of multifunctional $\mathrm{Ca}^{2+} /$ calmodulin-dependent protein kinase isoforms in rat brain. J. Neurosci., 15, 6797-6808.

Burgin,K.E., Waxham,M.N., Rickling,S., Westgate,S.A., Mobley,W.C. and Kelly,P.T. (1990) In situ hybridization histochemistry of $\mathrm{Ca}^{2+}$ / calmodulin-dependent protein kinase in developing rat brain. $J$. Neurosci., 10, 1788-1798.

Campbell,K.P. and MacLennan,D.H. (1982) A calmodulin-dependent protein kinase system from skeletal muscle sarcoplasmic reticulum. J. Biol. Chem., 257, 1238-1246.

Collinge,M., Matrisian,P.E., Zimmer,W.E., Shattuck,R.L., Lukas,T.J., van Eldik,L.J. and Watterson,D.M. (1992) Structure and expression of a calcium-binding protein gene contained within a calmodulin-regulated protein kinase gene. Mol. Cell. Biol., 12, 2359-2371.

De Koninck,P. and Schulman,H. (1998) Sensitivity of CaM kinase II to the frequency of $\mathrm{Ca}^{2+}$ oscillations. Science, 279, 227-230.

Edman,C.F. and Schulman,H. (1994) Identification and characterization of $\delta_{\mathrm{B}}-\mathrm{CaM}$ kinase and $\delta_{\mathrm{C}}-\mathrm{CaM}$ kinase from rat heart, two new multifunctional $\mathrm{Ca}^{2+} /$ calmodulin-dependent protein kinase isoforms. Biochim. Biophys. Acta, 1221, 89-101.

Giese,K.P., Fedorov,N.B., Filipkowski,R.K. and Silva,A.J. (1998) Autophosphorylation at $\mathrm{Thr}^{286}$ of the $\alpha$ calcium-calmodulin kinase II in LTP and learning. Science, 279, 870-873.

Hain,J., Onoue,H., Mayrleitner,M., Fleischer,S. and Schindler,H. (1995) Phosphorylation modulates the function of the calcium release channel of sarcoplasmic reticulum from cardiac muscle. J. Biol. Chem., 270, 2074-2081.

Hanson,P.I., Meyer,T., Stryer,L. and Schulman,H. (1994) Dual role of calmodulin in autophosphorylation of multifunctional CaM kinase may underlie decoding of calcium signals. Neuron, 12, 943-956. 
Heist,K., Srinivasan,M. and Schulman,H. (1998) Phosphorylation at the nuclear localization signal of $\mathrm{Ca}^{2+} /$ calmodulin-dependent protein kinase II blocks its nuclear targeting. J. Biol. Chem., 273, 1976319771.

Hubbard,M.J. and Cohen,P. (1993) On target with a new mechanism for the regulation of protein phosphorylation. Trends Biochem. Sci., 18, $172-177$.

Johnson,J.A., Gray,M.O., Chen,C.H. and Mochly-Rosen,D. (1996) A protein kinase $\mathrm{C}$ translocation inhibitor as an isozyme-selective antagonist of cardiac function. J. Biol. Chem., 271, 24962-24966.

Kanaseki,T., Ikeuchi,Y., Sugiura,H. and Yamauchi,T. (1991) Structural features of $\mathrm{Ca}^{2+} /$ calmodulin-dependent protein kinase II revealed by electron microscopy. J. Cell Biol., 115, 1049-1060.

Karls,U., Müller,U., Gilbert,D.J., Copeland,N.G., Jenkins,N.A. and Harbers,K. (1992) Structure, expression and chromosome location of the gene for the $\beta$ subunit of brain-specific $\mathrm{Ca}^{2+} /$ calmodulin-dependent protein kinase II identified by transgene integration in an embryonic lethal mouse mutant. Mol. Cell. Biol., 12, 3644-3652.

Kelly,P.T., McGuinness,T.L. and Greengard,P. (1984) Evidence that the major postsynaptic density protein is a component of a $\mathrm{Ca}^{2+}$ / calmodulin-dependent protein kinase. Proc. Natl Acad. Sci. USA, 81, 945-949.

Leibovitch,S.A., Guillier,M., Lenormand,J.L. and Leibovitch,M.P. (1993) $\mathrm{p} 34^{\mathrm{cdc} 2}$ protein is complexed with the c-mos protein in rat skeletal muscle. Oncogene, 8, 2361-2369.

Lin,C.R., Kapiloff,M.S., Durgerian,S., Tatemoto,K., Russo,A.F., Hanson,P., Schulman,H. and Rosenfeld,M.G. (1987) Molecular cloning of a brain-specific calcium/calmodulin-dependent protein kinase. Proc. Natl Acad. Sci. USA, 84, 5962-5966.

Mayer,P., Möhlig,M., Schatz,H. and Pfeiffer,A. (1993) Characterization of $\gamma$ - and $\delta$-subunits of $\mathrm{Ca}^{2+} /$ calmodulin-dependent protein kinase II in rat gastric mucosal cell populations. FEBS Lett., 333, 315-318.

Mays,R.W., Siemers,K.A., Fritz,B.A., Lowe,A.W., van Meer,G. and Nelson,W.J. (1995) Hierarchy of mechanisms involved in generating $\mathrm{Na} / \mathrm{K}-\mathrm{ATPase}$ polarity in MDCK epithelial cells. J. Cell Biol., 130, $1105-1115$.

McNeill,R.B. and Colbran,R.J. (1995) Interaction of autophosphorylated $\mathrm{Ca}^{2+}$ /calmodulin-dependent protein kinase II with neuronal cytoskeletal proteins. J. Biol. Chem., 270, 10043-10049.

Means,A.R., Cruzalegui,F.H., LeMaguerese,B., Needlemann,D.S. Slaughter,G.R. and Ono,T. (1991) A novel $\mathrm{Ca}^{2+} /$ calmodulin-dependent protein kinase and a male germ cell-specific calmodulin-binding protein are derived from the same gene. Mol. Cell. Biol., 11, 39603971.

Meyer,T., Hanson,P.I., Stryer,L. and Schulman,H. (1992) Calmodulin trapping by calcium-calmodulin-dependent protein kinase. Science, 256, 1199-1202.

Mochly-Rosen,D. (1995) Localization of protein kinases by anchoring proteins: a theme in signal transduction. Science, 268, 247-251.

Mukherji,S. and Soderling,T.R. (1994) Regulation of $\mathrm{Ca}^{2+} /$ calmodulindependent protein kinase II by inter- and intrasubunit-catalyzed autophosphorylations. J. Biol. Chem., 269, 13744-13747.

Nghiem,P., Saati,S.M., Martens,C.L., Gardner,P. and Schulman,H. (1993) Cloning and analysis of two new isoforms of multifunctional $\mathrm{Ca}^{2+} /$ calmodulin-dependent protein kinase. J. Biol. Chem., 268, 5471-5479.

Ohmstede,C.A., Bland,M.M., Merril,B.M. and Sahyoun,N. (1991) Relationship of genes encoding $\mathrm{Ca}^{2+} /$ calmodulin-dependent protein kinase Gr and calspermin: a gene within a gene. Proc. Natl Acad. Sci. USA, 88, 5784-5788.

Omkumar,R.V., Kiely,M.J., Rosenstein,A.J., Min,K.T. and Kennedy,M.B. (1996) Identification of a phosphorylation site for calcium/calmodulindependent protein kinase II in the NR2B subunit of the $N$-methyl-Daspartate receptor. J. Biol. Chem., 271, 31670-31678.

Pawson,T. and Scott,J.D. (1997) Signaling through scaffold, anchoring and adaptor proteins. Science, 278, 2075-2080.

Ramirez,M.T., Zhao,X.L., Schulman,H. and Brown,J.H. (1997) The nuclear $\delta_{\mathrm{B}}$ isoform of $\mathrm{Ca}^{2+} /$ calmodulin-dependent protein kinase II regulates atrial natriuretic factor gene expression in ventricular myocytes. J. Biol. Chem., 272, 31203-31208.

Rosenmund,C., Carr,D.W., Bergeson,S.E., Nilaver,G., Scott,J.D. and Westbrook,G.L. (1994) Anchoring of protein kinase A is required for modulation of AMPA/kainate receptors on hippocampal neurons. Nature, 368, 853-856.

Sahyoun,N., Le Vine,H.,III, Bronson,D., Siegel-Greenstein,F. and Cuatrecasas,P. (1985) Cytoskeletal calmodulin-dependent protein kinase. Characterization, solubilization and purification from rat brain. J. Biol. Chem., 260, 1230-1237.
Saito,A., Seiler,S., Chu,A. and Fleischer,S. (1984) Preparation and morphology of sarcoplasmic reticulum terminal cisternae from rabbit skeletal muscle. J. Cell Biol., 99, 875-885.

Saitoh,T. and Schwartz,J.H. (1985) Phosphorylation-dependent subcellular translocation of a $\mathrm{Ca}^{2+} /$ calmodulin-dependent protein kinase produces an autonomous enzyme in Aplysia neurons. J. Cell Biol., 100, 835-842.

Sakagami,H. and Kondo,H. (1993) Differential expression of mRNAs encoding $\gamma$ and $\delta$ subunits of $\mathrm{Ca}^{2+} /$ calmodulin-dependent protein kinase type II (CaM kinase II) in the mature and postnatally developing rat brain. Mol. Brain Res., 20, 51-63.

Sakaguchi,M., Mihara,K. and Sato,R. (1987) A short amino-terminal segment of microsomal cytochrome P-450 functions both as an insertion signal and as a stop-transfer sequence. EMBO J., 6, 24252431.

Schatz,G. and Dobberstein,B. (1996) Common principles of protein translocation across membranes. Science, 271, 1519-1526.

Shen,K. and Meyer,T. (1998) In vivo and in vitro characterization of the sequence requirement for oligomer formation of $\mathrm{Ca}^{2+} /$ calmodulindependent protein kinase II $\alpha$. J. Neurochem., 70, 96-104.

Shirinsky,V.P., Vorotnikov,A.V., Birukov,K.G., Nanaev,A.K., Collinge, M., Lukas,T.J., Sellers,J.R. and Watterson,D.M. (1993) A kinaserelated protein stabilizes unphosphorylated smooth muscle myosin minifilaments in the presence of ATP. J. Biol. Chem., 268, 1657816583.

Silver,D.L., Vorotnikov,A.V., Watterson,D.M., Shirinsky,V.P. and Sellers,J.R. (1997) Sites of interaction between kinase-related protein and smooth muscle myosin. J. Biol. Chem., 272, 25353-25359.

Srinivasan,M., Edman,C.F. and Schulman,H. (1994) Alternative splicing introduces a nuclear localization signal that targets multifunctional CaM kinase to the nucleus. J. Cell Biol., 126, 839-852.

Strack,S., Choi,S., Lovinger,D.M. and Colbran,R.J. (1997) Translocation of autophosphorylated calcium/calmodulin-dependent protein kinase II to the postsynaptic density. J. Biol. Chem., 272, 13467-13470.

Sugai,R., Takeuchi,M., Okuno,S. and Fujisawa,H. (1996) Molecular cloning of a novel protein containing the association domain of calmodulin-dependent protein kinase II. J. Biochem., 120, 773-779.

Szczesna-Skorupa,E., Browne,N., Mead,D. and Kemper,B. (1988) Positive charges at the $\mathrm{NH}_{2}$ terminus convert the membrane-anchor signal peptide of cytochrome P-450 to a secretory signal peptide. Proc. Natl Acad. Sci. USA, 85, 738-742.

Tobimatsu,T. and Fujisawa,H. (1989) Tissue-specific expression of four types of rat calmodulin-dependent protein kinase II mRNAs. J. Biol. Chem., 264, 17907-17912.

Urquidi,V. and Ashcroft,S.J.H. (1995) A novel pancreatic beta-cell isoform of calcium/calmodulin dependent protein kinase II ( $\beta_{3}$ isoform) contains a proline-rich tandem repeat in the association domain. FEBS Lett., 358, 23-26.

Wang,J. and Best,P.M. (1992) Inactivation of the sarcoplasmic reticulum calcium channel by protein kinase. Nature, 359, 739-741.

Wegener,A.D., Simmermann,H.K., Lindemann,J.P. and Jones,L.R. (1989) Phospholamban phosphorylation in intact ventricles. Phosphorylation of serine 16 and threonine 17 in response to beta-adrenergic stimulation. J. Biol. Chem., 264, 11468-11476.

Witcher,D.R., Kovacs,R.J., Schulman,H., Cefali,D.C. and Jones,L.R. (1991) Unique phosphorylation site on the cardiac ryanodine receptor regulates calcium channel activity. J. Biol. Chem., 17, 11144-11152.

Xu,A., Hawkins,C. and Narayanan,N. (1993) Phosphorylation and activation of the $\mathrm{Ca}^{2+}$-pumping ATPase of cardiac sarcoplasmic reticulum by $\mathrm{Ca}^{2+} /$ calmodulin-dependent protein kinase. J. Biol. Chem., 268, 8394-8397.

Yoshimura,Y. and Yamauchi,T. (1997) Phosphorylation-dependent reversible association of $\mathrm{Ca}^{2+} /$ calmodulin-dependent protein kinase II with the postsynaptic densities. J. Biol. Chem., 272, 26354-26359.

Received June 19, 1998; revised and accepted August 11, 1998

\section{Note added in proof}

One of the PSD proteins that interacts with $\mathrm{CaM}$ kinase II has been shown to be the NR2B subunit of the NMDA receptor which may serve as a target for translocation of the autophosphorylated kinase to the PSD [Strack,S. and Colbran,R.J. (1998) Autophosphorylation-dependent targeting of calcium/calmodulin-dependent protein kinase II by the NR2B subunit of the N-methyl-D-aspartate receptor. J. Biol. Chem., 273 , 20689-20692]. 